\title{
Valve Fault Diagnosis in Internal Combustion Engines Using Acoustic Emission and Artificial Neural Network
}

\author{
S. M. Jafari, H. Mehdigholi, and M. Behzad \\ School of Mechanical Engineering, Sharif University of Technology, Azadi Street, Tehran 145888-9694, Iran \\ Correspondence should be addressed to M. Behzad; m_behzad@sharif.edu
}

Received 9 May 2013; Accepted 19 September 2013; Published 25 February 2014

Academic Editor: Gyuhae Park

Copyright (C) 2014 S. M. Jafari et al. This is an open access article distributed under the Creative Commons Attribution License, which permits unrestricted use, distribution, and reproduction in any medium, provided the original work is properly cited.

This paper presents the potential of acoustic emission (AE) technique to detect valve damage in internal combustion engines. The cylinder head of a spark-ignited engine was used as the experimental setup. The effect of three types of valve damage (clearance, semicrack, and notch) on valve leakage was investigated. The experimental results showed that AE is an effective method to detect damage and the type of damage in valves in both of the time and frequency domains. An artificial neural network was trained based on time domain analysis using $\mathrm{AE}$ parametric features $\left(\mathrm{AE}_{\mathrm{rms}}\right.$, count, absolute $\mathrm{AE}$ energy, maximum signal amplitude, and average signal level). The network consisted of five, six, and five nodes in the input, hidden, and output layers, respectively. The results of the trained system showed that the AE technique could be used to identify the type of damage and its location.

\section{Introduction}

The valves in an internal combustion engine play a significant role in engine performance. Moreover they are the most important components in the valvetrain and face high temperatures and gas pressure impulses. In the failure analysis of a valvetrain, valve failures represent the most common problems. The major causes of valve failure are distortion of the valve seat, deposits on the valve, small tappet clearance, burnt valve, erosion of valves, heat fatigue, pitting, breaks, and wear $[1,2]$. In recent years, implementing condition monitoring techniques for internal combustion (IC) engines has led to reliable nonintrusive methods for engine diagnosis [3].

It is possible for turbulent flow, such as air flow through valves, to induce vibrations in their structures. The frequency of oscillation depends on the stiffness of the structure. The amplitude depends on mean flow velocity and on how close the forcing frequency is to the natural frequency of the structure. Lighthill's formulation of the aeroacoustic problem showed that the mixing region of a jet could be equated to a volume of quadrupoles with strength proportional to the stress tensor in the moving fluid. Such a mathematical formulation allows radiated jet acoustic power levels to be estimated and proportional to $v^{8}[4]$ :

$$
P_{s}=\frac{\rho v^{8} d^{2}}{\alpha^{5}}
$$

where $P_{s}$ is the sound power (W), $d$ is the diameter of the leakage hole, $v$ is the average turbulence jet velocity $(\mathrm{m} / \mathrm{s})$, and $\alpha$ is the sound velocity in the fluid $(\mathrm{m} / \mathrm{s})$. Equation (1) clearly shows that flow velocity has the most effect on generating sound. The mass of air flow in/out to the cylinder is related to the air density, velocity, and area through which the gas flows:

$$
\dot{m}=\rho A v,
$$

where $\dot{m}$ is the mass flow $(\mathrm{kg} / \mathrm{s}), A$ represents the area through which the gas flows $\left(\mathrm{m}^{2}\right), \rho$ relates the flow density $\left(\mathrm{kg} / \mathrm{m}^{3}\right)$, and $v$ is the flow velocity $(\mathrm{m} / \mathrm{s})$. In this study, the valve diameters were $d_{\mathrm{ev}}=30.52 \mathrm{~mm}$ for the exhaust valve and $d_{\mathrm{iv}}=36.24 \mathrm{~mm}$ for the intake valve.

Vibration analysis is a well-established technique for fault diagnosis in rotating machinery, particularly for IC engines. Application of this technique to an IC engine is strongly 


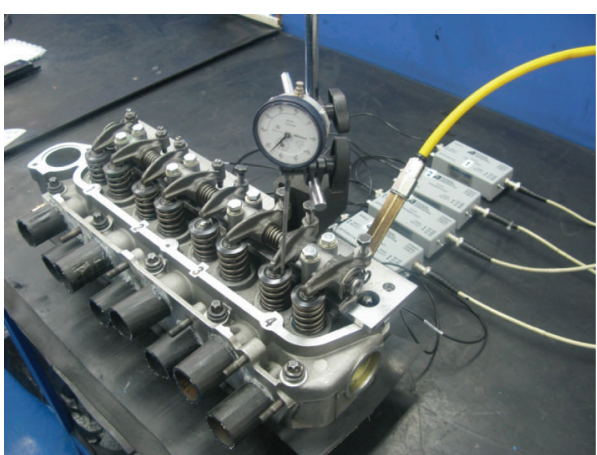

(a)

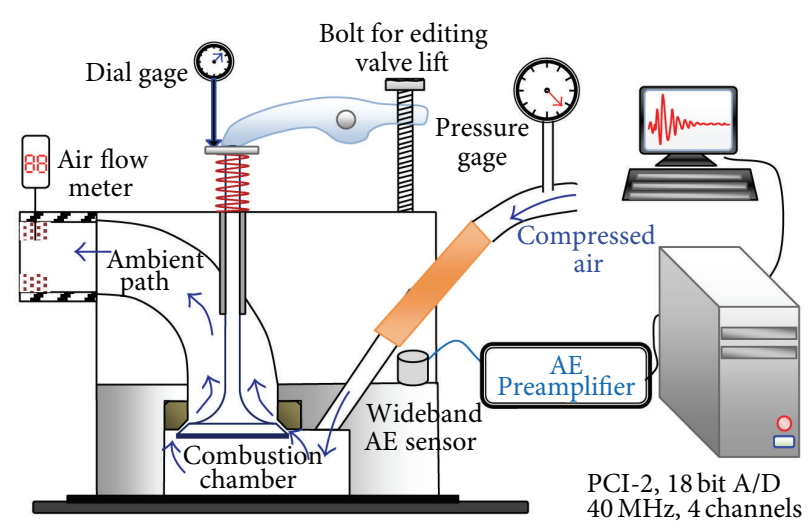

(b)

FIgURE 1: Test rig overview. (a) AE sensors positions and (b) schematic of measurement system.

affected by engine faults, auxiliary devices, and mechanical events in the engine [5]. The high signal-to-noise ratio characteristic of the AE signal in comparison to vibration analysis has led to widespread interest in the last decade for $\mathrm{AE}$ application in the field of fault diagnosis of engines [6].

Recent research has shown the success of AE applications for IC engines. Different engine faults and processes have been simulated, including cylinder misfire [7], exhaust manifold gasket leakage [8], piston ring/cylinder liner scuffing [9], fuel injection problems and processes [10-13], cylinder pressure [14], engine lubrication [15], and valve leakage (VL) [16-21].

There are comprehensive investigation methods for fault diagnostic of VL using the AE method. All of them simulate the VL fault using valve clearance change [16-21]; however, significant causes exist besides clearance that eventuate in VL such as valve head crack and valve head notch. Using AE signals in VL to identify the type of fault is a new area of research that was addressed in this study. Three fault types (valve clearance, valve head crack, and valve head notch) were artificially simulated as follows.

(i) The valve clearance fault was simulated by a very small lift in valve.

(ii) Valve head crack fault was simulated by a semicrack on the exhaust/intake valve head.

(iii) The removal of a small amount of valve head material simulates valve head notch.

The test rig was a cylinder head for a spark-ignited engine. The aim of this investigation at this stage was to use AE signals in VL to identify fault types in an engine that is not running.

\section{Experimental Setup}

2.1. Test Rig and Measurement System. The test setup consisted of the aluminium cylinder head of a small four-cylinder spark-ignited engine. Figure 1(a) shows the position of four wideband AE sensors on the cylinder head and a schematic of the test rig. Pressurized air entered the combustion chamber through the spark plug hole. Air flow was measured using an air flow meter with an accuracy of $1 \mathrm{~L} / \mathrm{min}$.

2.2. AE Data Acquisition System. AE signals were acquired using four wideband sensors. The operating frequency was filtered from $100 \mathrm{kHz}$ to $1 \mathrm{MHz}$. The AE sensors were coupled to the cylinder head using thin layers of vacuum grease. The signals were then amplified using PAC 2/4/6 preamplifiers before being recorded. Then the signals were digitized using a PAC PCI-2 (18 bit A/D, $40 \mathrm{MHz}, 4$ channels) AE data acquisition system. Raw data was acquired at a sampling rate of $2 \mathrm{MHz}$. AE sensors were mounted on the cylinder head near the spark plug hole on all four cylinders, as shown in Figure 1.

2.3. Simulated Valve Fault Types. Three types of valve fault were artificially simulated. The test procedures were similar for all cases: inserting pressurized air through the spark plug hole and leakage measurement at the target valve port caused by its faulty valve. These faults are detailed below.

(i) Semicracked Valve. This fault was simulated by making a semicrack on the valve head using the wire cut method. The exhaust valve of cylinder number 1 and intake valve of cylinder number 2 were simulated using this method. The area of the removed surface of the valve head was $0.27 \times 3.72 \mathrm{~mm}$, as shown in Figure 2.

(ii) Notched Valve. This fault was simulated by removing a slight amount of material from the seating face width of the exhaust valve, as shown in Figure 3.

(iii) Valve Clearance. This fault was simulated by a $0.1 \mathrm{~mm}$ lift to the exhaust and intake valves of cylinder number 4 . Figure 4 shows a healthy valve in cylinder 4 that has no leakage at zero lift. External lift simulated extra clearance.

2.4. Test Procedure. The valves of cylinder 4 were healthy and they had no leakage at zero lift; therefore the exhaust and intake valves were separately lifted $0.1 \mathrm{~mm}$ using a lifter bolt. 


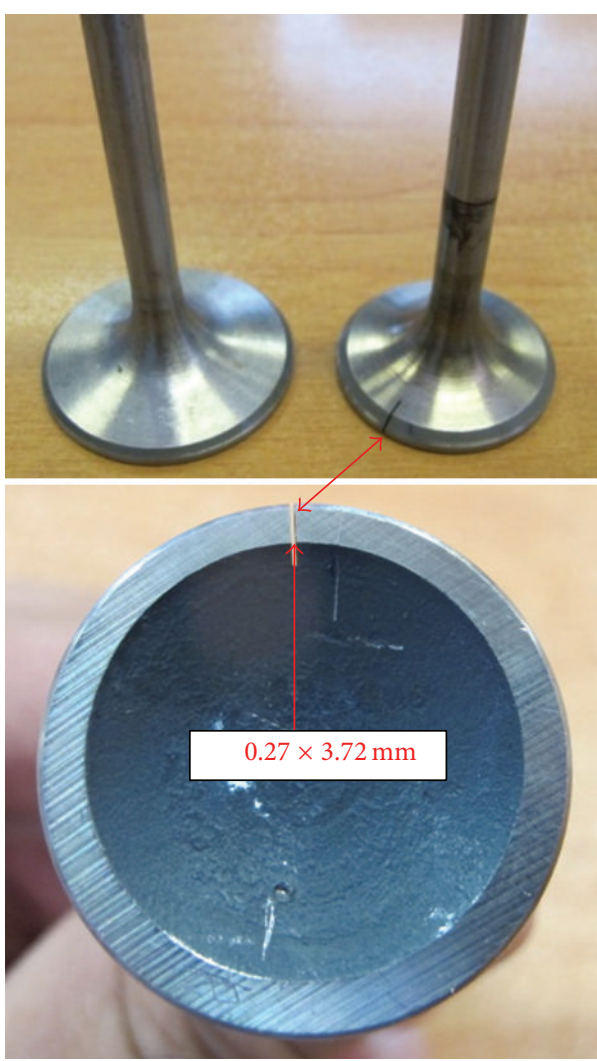

(a)
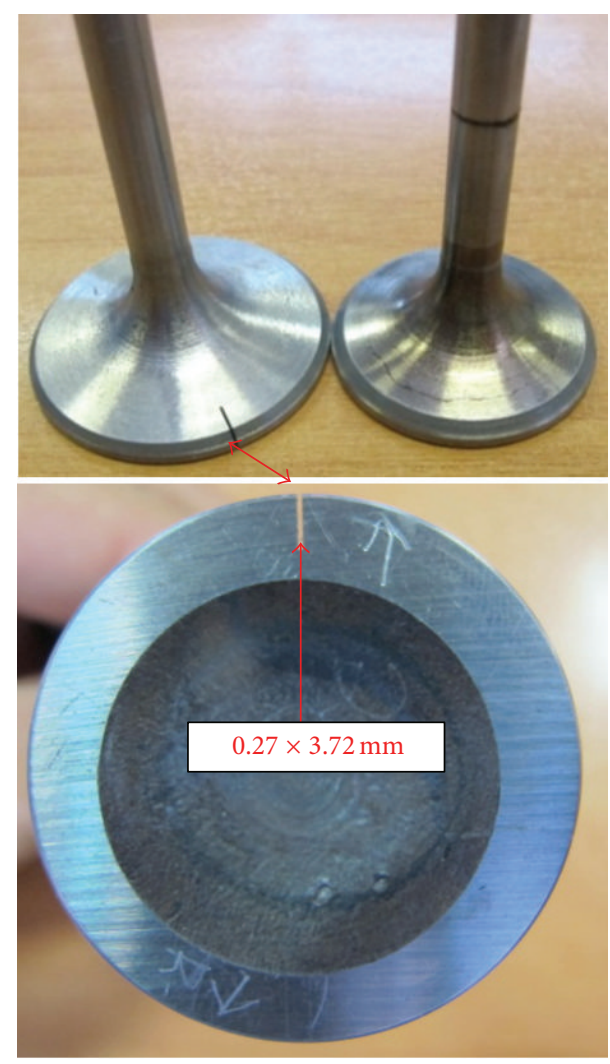

(b)

Figure 2: Semicracked valves. (a) Cylinder number 1 and (b) cylinder nymber 2.
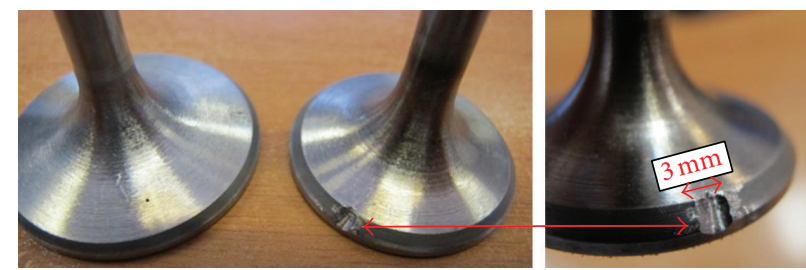

FIGURE 3: Notched exhaust valve of cylinder number 3.

Lift was measured by a dial gauge with an accuracy of $0.01 \mathrm{~mm}$ as shown in Figure 1(b). At each step, one valve (exhaust or intake) was opened. Inlet pressurized air was controlled using a pressure regulator from 1 to 6 bar. At each pressure, all parameters were recorded ( $4 \mathrm{AE}$ sensors, leakage rate, lift, and inlet air pressure). There was no lift for cylinders 1 to 3 because one valve of each cylinder was faulty and had leakage at zero lift.

\section{Results and Discussion}

3.1. Valve Leakage Results. Figure 5 shows the VL rate for all four cylinders versus inlet pressurized air for the different fault types. As expected, leakage rate increased as pressure increased for all fault types.
3.2. Time Domain Signal Analysis. Analysis in the time domain reveals the overall signal amplitude, periodic features, and AE signal type. Figures 6, 7, 8, and 9 show the raw $\mathrm{AE}$ waveform caused by $\mathrm{VL}$ at each cylinder. The data in Figures 6-9 are for the AE sensor nearest to the studied cylinder (sensors 1-4 for cylinder 1-4, resp.). Figure 10 shows the AE signals recorded for healthy valves with no leakage at zero lift and healthy valves from the same cylinders with no leakage at zero lift. Figures 6-9 show the AE signal acquired for $0.02 \mathrm{sec}$.

Equation (1) shows that the acoustic power level was proportional to $v^{8}$, which means that acoustic power level was strongly dependent on leakage velocity; therefore, an increase in the leakage rate caused a very clear change in AE signal amplitude. 


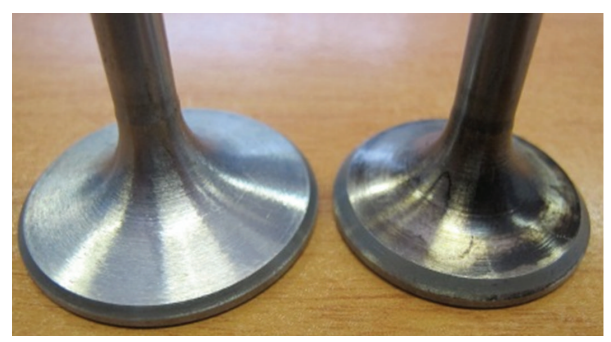

FIGURE 4: Healthy valves of cylinder number 4. Clearance fault was simulated by lift on valves.

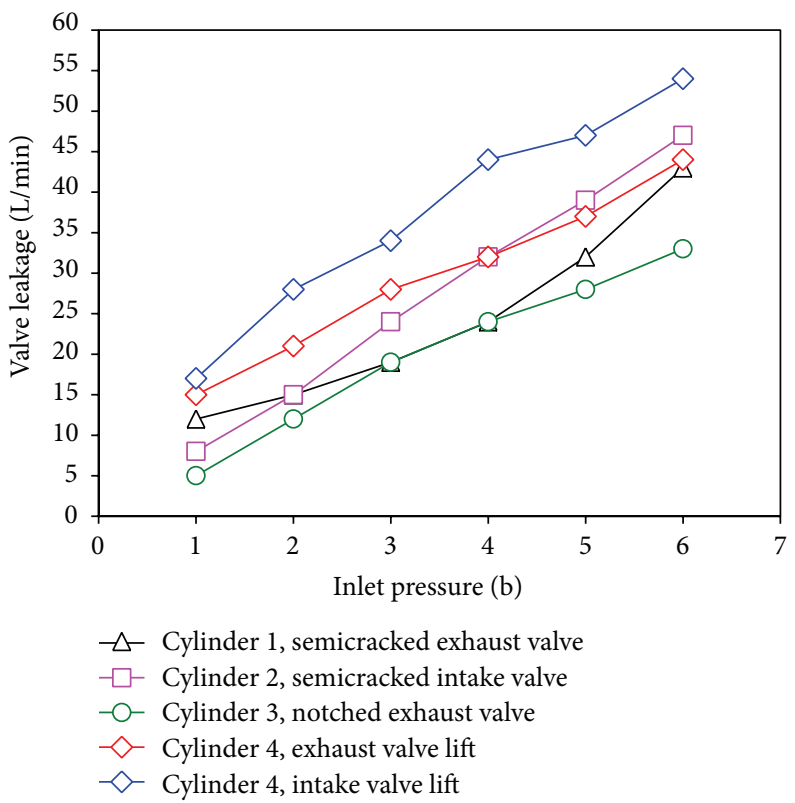

FIGURE 5: VL rate of all cylinders versus inlet pressurized air.

In all cases, it was observed that AE signals were typically continuous and the amplitude of the AE signal increased as the inlet pressure increased. Figures 6-8 show the results for semicracked and notched valves in cylinders $1-3$. It can be seen that the AE signals were very similar in wave form and amplitude; thus, it was not easy to distinguish between signals produced by different faults.

Figure 9 shows the results for the lifted valves in cylinder 4 and indicates that the signals have only a slightly different wave. It can be seen that the AE signals recorded from the exhaust and intake lifted valves are almost the same.

The signals in Figure 10 can be regarded as basic AE amplitudes for VL and are related to the existence of compressed air in the cylinder chamber, the test setup, environment, and background noise.

3.3. Frequency Domain Signal Analysis. Frequency analysis of the AE signal from the VL shows the energy distribution of the signal in the frequency domain. Figures 11, 12, 13 , and 14 show the power spectral density (PSD) of the signals shown in Figures 6-9. Frequency analysis of the AE signals demonstrates that gas leakage generates broadband
AE signal. Moreover comparing Figure 15 for the spectrum of healthy valves with those in Figures 11-14 shows that there are some picks in the spectrum of faulty valves, while these do not exist in healthy ones.

In Figures 11-13, the frequency analysis of AE signals for semicracked and notched valves exhibited similar behavior, as would be expected from their waveforms in Figures 6-8. Figure 14 shows the results of frequency analysis of the $\mathrm{AE}$ signal from the exhaust and intake VL of cylinder 4 . It can be seen that both exhaust and intake were very similar in their PSD analyses. Figure 15 presents the PSD analysis of the AE signal recorded for healthy valves with no leakage.

Although the frequency analysis detected the healthy and simulated faulty valves in the frequency domain, this method faced difficulties in showing a clear difference between the types of defective valves. For example, it was difficult to distinguish between the semicracked and notched valves. Separating the different types of faults requires an expert and systematic method. An artificial neural network (ANN) based on AE parameters extracted from raw AE signals was utilized for this stage. The parameters were the AE basic parameters: $\mathrm{AE}_{\mathrm{rms}}$, count, absolute $\mathrm{AE}$ energy, maximum signal amplitude, and average signal level. 


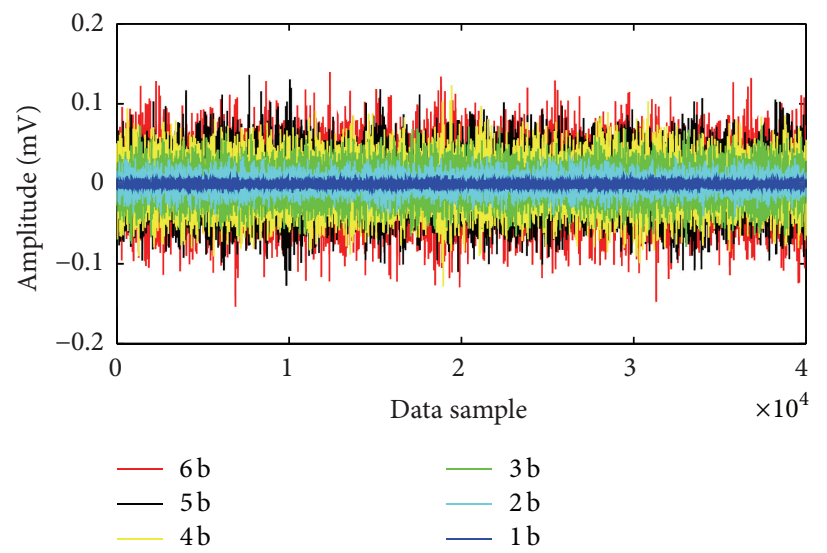

Figure 6: Raw AE signal due to VL through semicracked exhaust valve in cylinder 1.

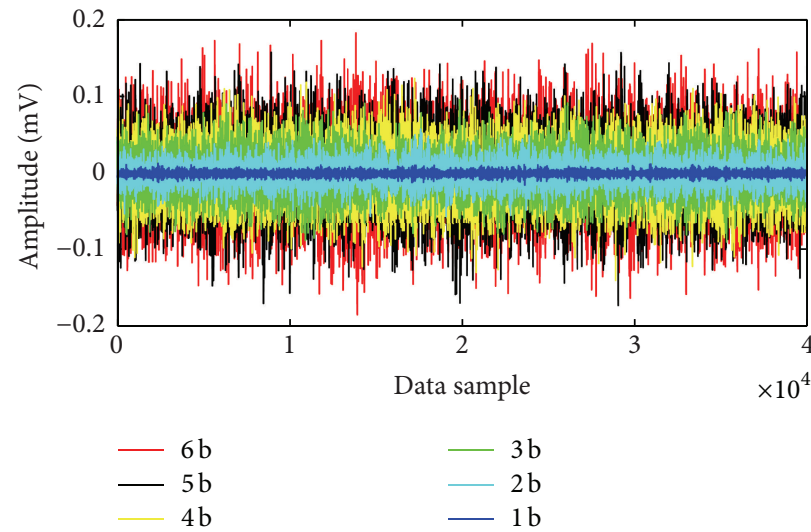

Figure 7: Raw AE signal due to VL through semicracked intake valve in cylinder 2.

\section{Artificial Neural Network for Determining Valve Fault Type}

Artificial neural networks (ANNs) can identify correlated patterns between the input data set and corresponding target values. ANNs have good ability for prediction, pattern recognition, data compression, and decision-making [22]. Figure 16 shows a model of an artificial neuron.

ANN was adopted to use five parameters $\left(\mathrm{AE}_{\mathrm{rms}}\right.$, count, absolute AE energy, maximum signal amplitude, average signal level) to identify valve fault type. The input layer consisted of five nodes corresponding to the five input features. The hidden layer had six nodes and the output layer had six nodes, of which five nodes represent the valve fault type and one node is reserved for the healthy condition. The output of each node is defined by the following sigmoid function:

$$
F\left(\text { net }_{i}\right)=F\left(\sum_{j} w_{i j} o_{i j}\right), \quad F(s)=\frac{1}{1-e^{-s}},
$$

where net is the training data, $w$ is the vector of weights, $o$ is vector of inputs, and $F(s)$ is the transfer function.

The backpropagation method was used to learn the weights between each pair of nodes. The total data set for
TABLE 1: Output condition meaning.

\begin{tabular}{ll}
\hline $\begin{array}{l}\text { Node } \\
\text { number }\end{array}$ & Valve fault type \\
\hline $\mathrm{O}_{1}$ & Cylinder 4, healthy valves, no leakage at zero valve lift \\
$\mathrm{O}_{2}$ & Cylinder 1, semicracked exhaust valve \\
$\mathrm{O}_{3}$ & Cylinder 2, semicracked intake valve \\
$\mathrm{O}_{4}$ & Cylinder 3, notched exhaust valve \\
$\mathrm{O}_{5}$ & Cylinder 4, valve clearance, exhaust valve lift \\
$\mathrm{O}_{6}$ & Cylinder 4, valve clearance, intake valve lift \\
\hline
\end{tabular}

each class was comprised of 200 data samples, and each data sample wa comprised of 40,000 data points. The 200 data samples were randomly divided into two equal groups, one for training and one for testing. Table 1 shows the output condition.

Figure 17 is a sample that shows the efficiency of maximum amplitude, $\mathrm{AE}_{\mathrm{rms}}$, and count in classifying the six classes of valve condition. As seen, some valve faults can be categorized visually, but other classes have very similar properties. A more efficient expert system is necessary to classify them with high performance. 


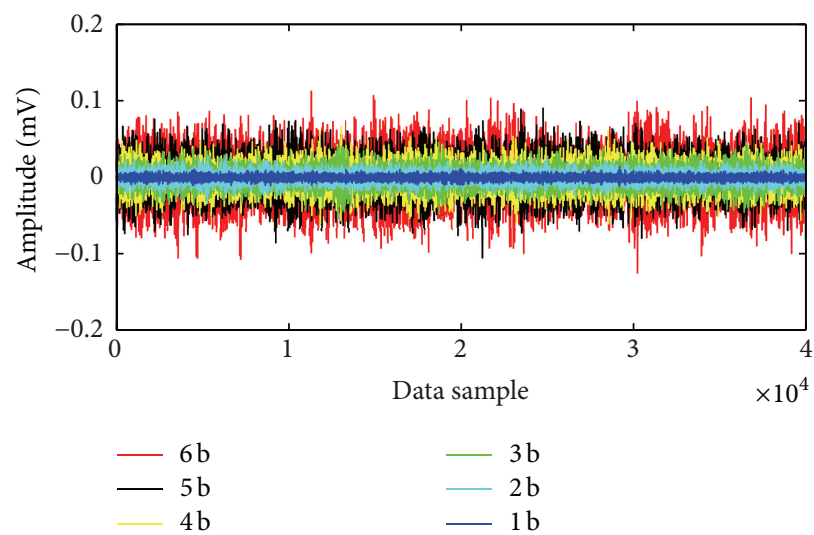

FIgURE 8: Raw AE signal due to VL through notched exhaust valve in cylinder 3.

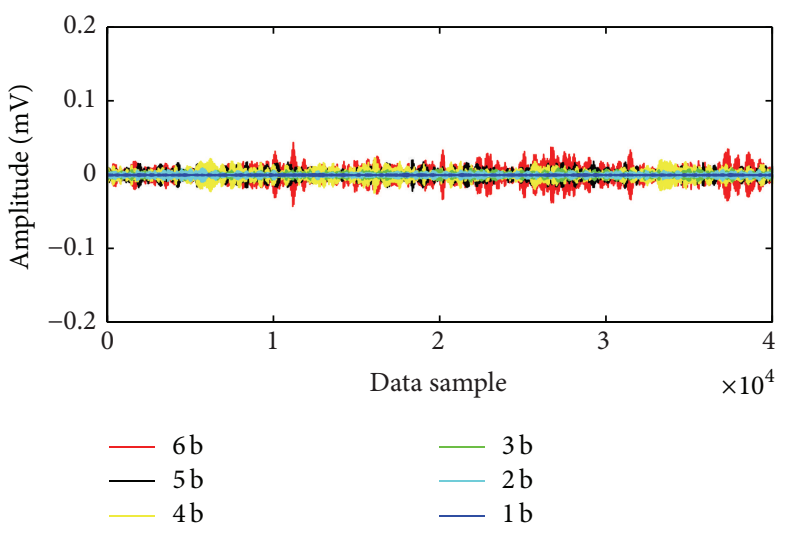

(a)

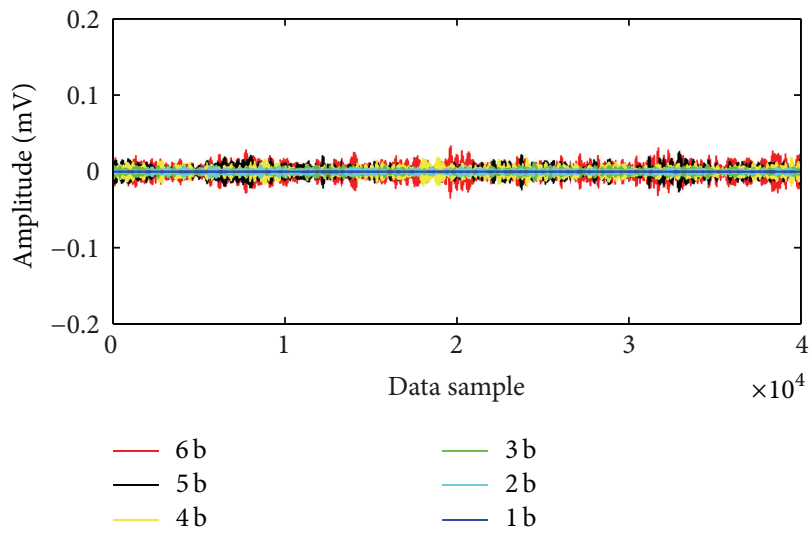

(b)

Figure 9: Raw AE signal due to leakage through lifted valve in cylinder 4. (a) $0.1 \mathrm{~mm}$ lifted exhaust valve and (b) $0.1 \mathrm{~mm}$ lifted intake valve.

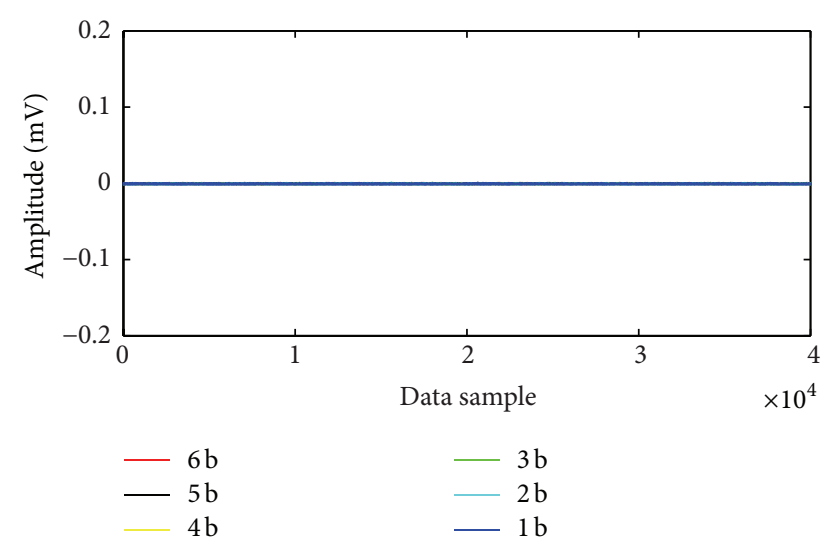

FIGURE 10: Raw AE signal relate to healthy valves with no leakage in cylinder 4 .

Table 2 presents the confusion matrix of the ANN method. The confusion matrix shows that ANN model was able to classify AE signals correctly. The most significant issue for a trained expert system is that the classifier may

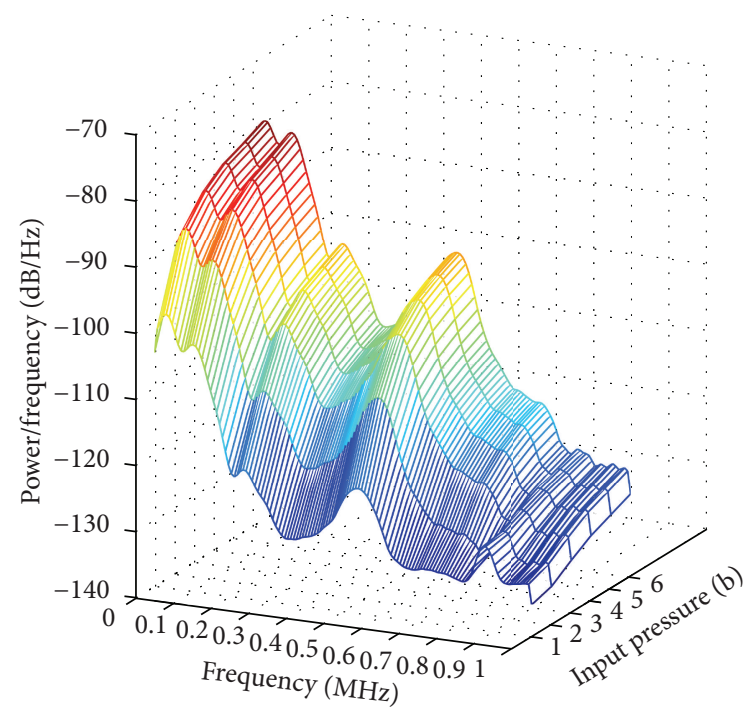

FIgure 11: Power spectral density of raw AE signal due to VL through semicracked exhaust valve in cylinder 1 versus time at 1-6 bar by sensor number 1 . 
TABLE 2: Confusion matrix of testing data for ANN.

\begin{tabular}{|c|c|c|c|c|c|c|c|c|c|c|c|c|c|c|c|c|}
\hline $\begin{array}{l}\text { Valve } \\
\text { condition }\end{array}$ & $\begin{array}{l}\text { Pressure } \\
\text { (bar) }\end{array}$ & $\mathrm{O}_{1}$ & $\mathrm{O}_{2}$ & $\mathrm{O}_{3}$ & $\mathrm{O}_{4}$ & $\mathrm{O}_{5}$ & $\mathrm{O}_{6}$ & Sensitivity (\%) & $\begin{array}{c}\text { Valve } \\
\text { condition }\end{array}$ & $\mathrm{O}_{1}$ & $\mathrm{O}_{2}$ & $\mathrm{O}_{3}$ & $\mathrm{O}_{4}$ & $\mathrm{O}_{5}$ & $\mathrm{O}_{6}$ & Sensitivity (\%) \\
\hline \multirow{6}{*}{$\mathrm{O}_{1}$} & 1 & 100 & 0 & 0 & 0 & 0 & 0 & \multirow{6}{*}{100} & \multirow{6}{*}{$\mathrm{O}_{4}$} & 0 & 3 & 0 & 97 & 0 & 0 & \multirow{6}{*}{100} \\
\hline & 2 & 100 & 0 & 0 & 0 & 0 & 0 & & & 0 & 0 & 0 & 100 & 0 & 0 & \\
\hline & 3 & 100 & 0 & 0 & 0 & 0 & 0 & & & 0 & 0 & 0 & 100 & 0 & 0 & \\
\hline & 4 & 100 & 0 & 0 & 0 & 0 & 0 & & & 0 & 0 & 0 & 100 & 0 & 0 & \\
\hline & 5 & 100 & 0 & 0 & 0 & 0 & 0 & & & 0 & 0 & 0 & 100 & 0 & 0 & \\
\hline & 6 & 100 & 0 & 0 & 0 & 0 & 0 & & & 0 & 0 & 0 & 100 & 0 & 0 & \\
\hline \multirow{6}{*}{$\mathrm{O}_{2}$} & 1 & 0 & 98 & 1 & 1 & 0 & 0 & \multirow{6}{*}{99} & \multirow{6}{*}{$\mathrm{O}_{5}$} & 0 & 0 & 0 & 0 & 88 & 12 & \multirow{6}{*}{79} \\
\hline & 2 & 0 & 100 & 0 & 0 & 0 & 0 & & & 0 & 0 & 0 & 0 & 67 & 33 & \\
\hline & 3 & 0 & 98 & 2 & 0 & 0 & 0 & & & 0 & 0 & 0 & 0 & 75 & 25 & \\
\hline & 4 & 0 & 100 & 0 & 0 & 0 & 0 & & & 0 & 0 & 0 & 0 & 86 & 14 & \\
\hline & 5 & 0 & 100 & 0 & 0 & 0 & 0 & & & 0 & 0 & 0 & 0 & 88 & 12 & \\
\hline & 6 & 0 & 100 & 0 & 0 & 0 & 0 & & & 0 & 0 & 0 & 0 & 69 & 31 & \\
\hline \multirow{6}{*}{$\mathrm{O}_{3}$} & 1 & 0 & 1 & 99 & 0 & 0 & 0 & \multirow{6}{*}{100} & \multirow{6}{*}{$\mathrm{O}_{6}$} & 0 & 0 & 0 & 0 & 7 & 93 & \multirow{6}{*}{75} \\
\hline & 2 & 0 & 0 & 100 & 0 & 0 & 0 & & & 0 & 0 & 0 & 0 & 27 & 73 & \\
\hline & 3 & 0 & 0 & 100 & 0 & 0 & 0 & & & 0 & 0 & 0 & 0 & 39 & 61 & \\
\hline & 4 & 0 & 0 & 100 & 0 & 0 & 0 & & & 0 & 0 & 0 & 0 & 28 & 72 & \\
\hline & 5 & 0 & 0 & 100 & 0 & 0 & 0 & & & 0 & 0 & 0 & 0 & 22 & 78 & \\
\hline & 6 & 0 & 2 & 98 & 0 & 0 & 0 & & & 0 & 0 & 0 & 0 & 27 & 73 & \\
\hline
\end{tabular}

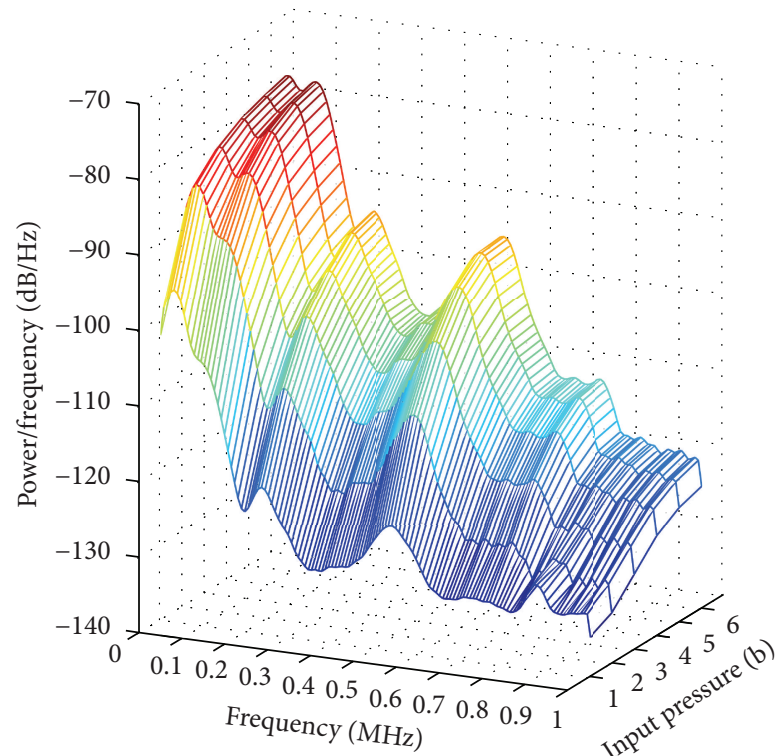

FIgure 12: Power spectral density of raw AE signal due to VL through semicracked intake valve in cylinder 2 .

detect a fault signal from a healthy signal. Table 2 shows that ANN detected faulty and healthy valves properly. All faulty signals were distinguished correctly from healthy signals. The ANN expert system performed well in differentiating the fault type of the valves. For example, it separated the semicracked exhaust valve (class $\mathrm{O}_{2}$ ) from the other faulty classes (classes from $\mathrm{O}_{3}$ to $\mathrm{O}_{6}$ ) intelligently. It can be seen from Figure 17 that $\mathrm{O}_{5}$ and $\mathrm{O}_{6}$ have very close properties and the ability of the

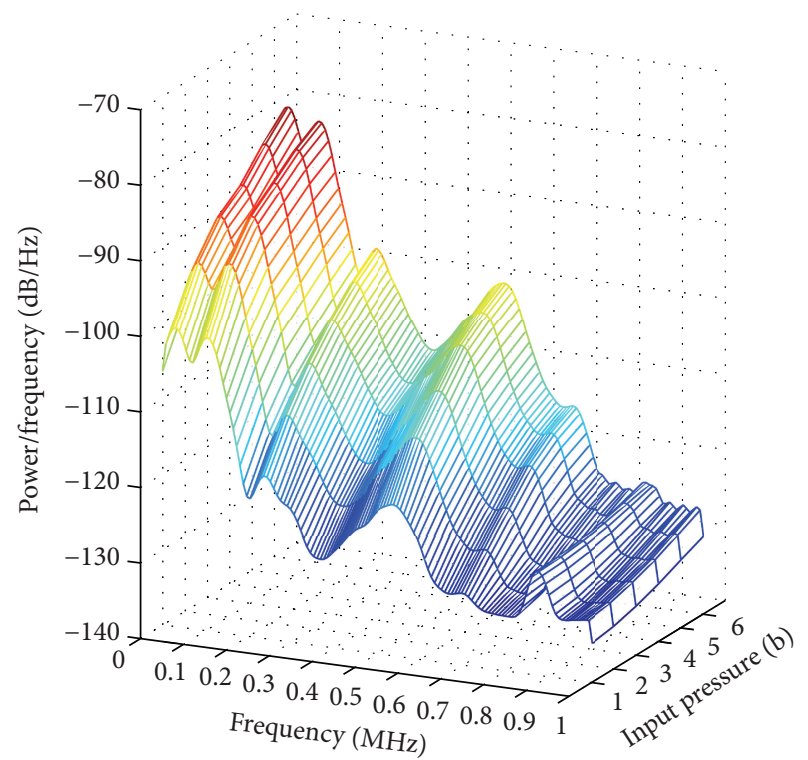

FIgURE 13: Power spectral density of raw AE signal due to VL through notched exhaust valve in cylinder 3 .

expert system in distinguishing between $\mathrm{O}_{5}$ and $\mathrm{O}_{6}$ was lower than other classes.

\section{Conclusion}

This study constructed an expert system based on acoustic emission data to distinguish between valve fault types. 


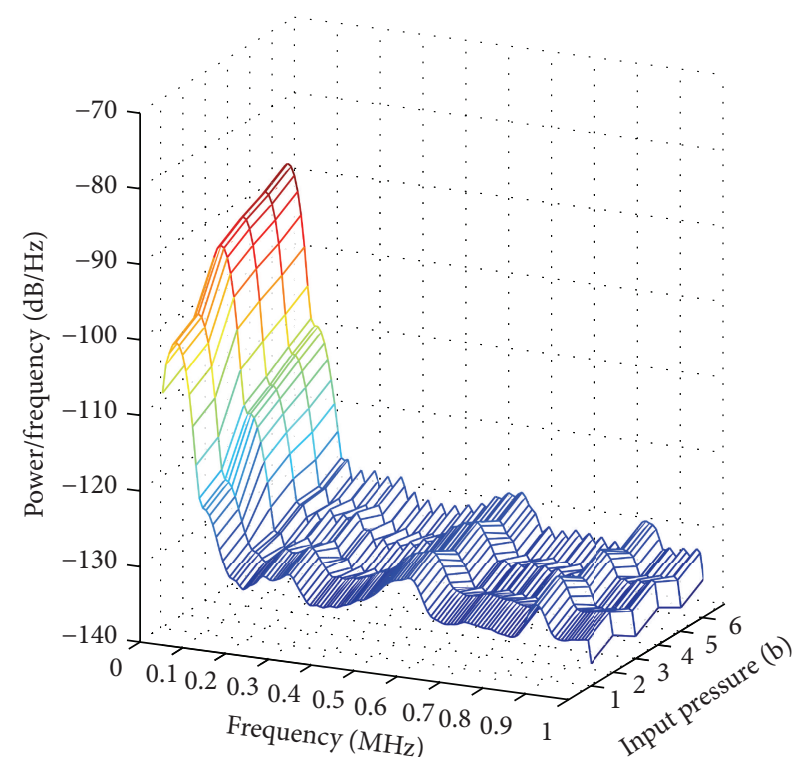

(a)

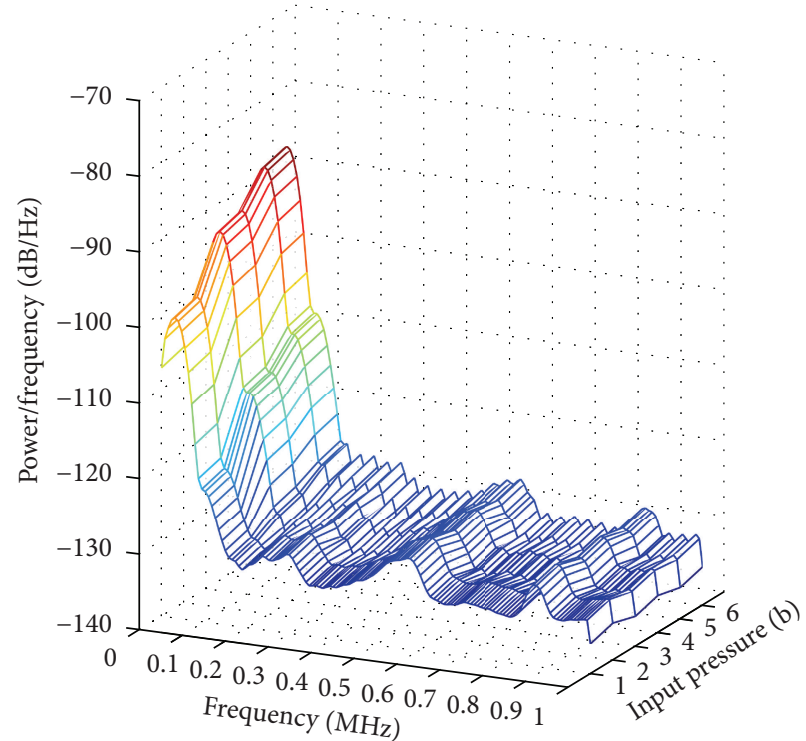

(b)

FIGURE 14: Power spectral density of raw AE signal due to VL through $0.1 \mathrm{~mm}$ lifted valve in cylinder 4. (a) Exhaust valve and (b) intake valve.

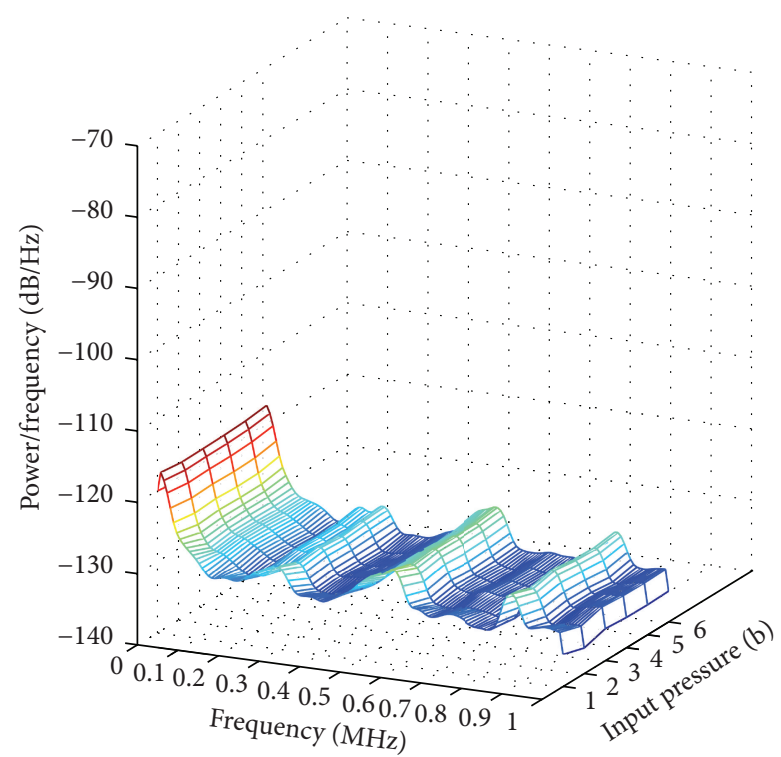

FIGURE 15: Power spectral density of raw AE signal for healthy valves with no leakage in cylinder 4 .

Three valve faults (cracked valve, notched valve, and valve clearance) were simulated and used in the cylinder head of an internal combustion gasoline engine. It was shown that using time and frequency domain analysis only detects the difference between faulty and healthy valves. Healthy valves have no leakage and their AE signals have low amplitude. In order to distinguish between the fault types in valves,

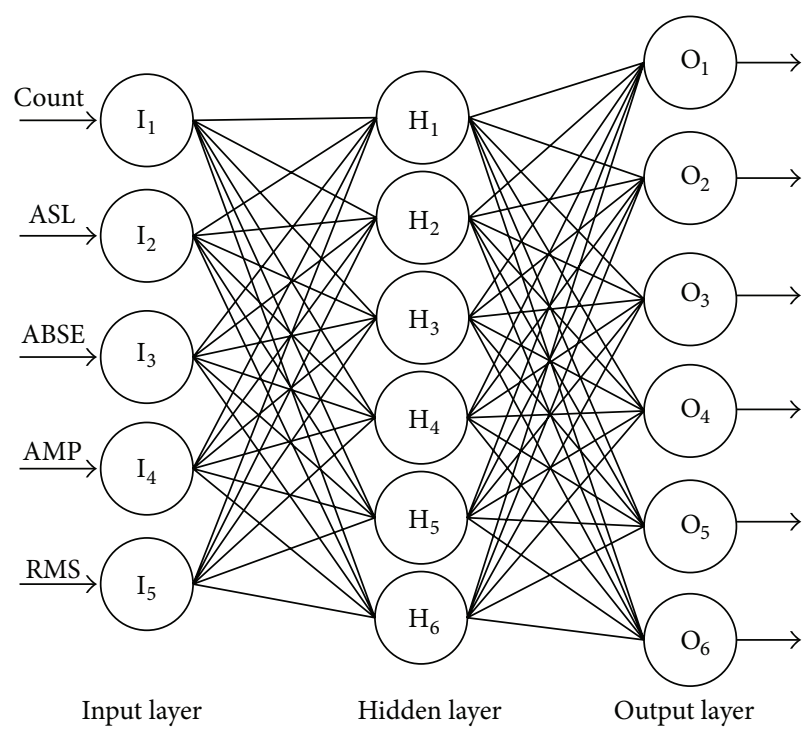

FIGURE 16: Artificial Neuron model.

an ANN was used based on AE features. It was trained using five $\mathrm{AE}$ parameters $\left(\mathrm{AE}_{\mathrm{rms}}\right.$, count, absolute $\mathrm{AE}$ energy, maximum signal amplitude, and average signal level) for fault separation. These parameters had very good correlation with valve leakage and ANN was well trained using random segmented data. The results from this expert system showed good performance (over 92\%) in distinguishing between faulty and healthy valves and fault types. 


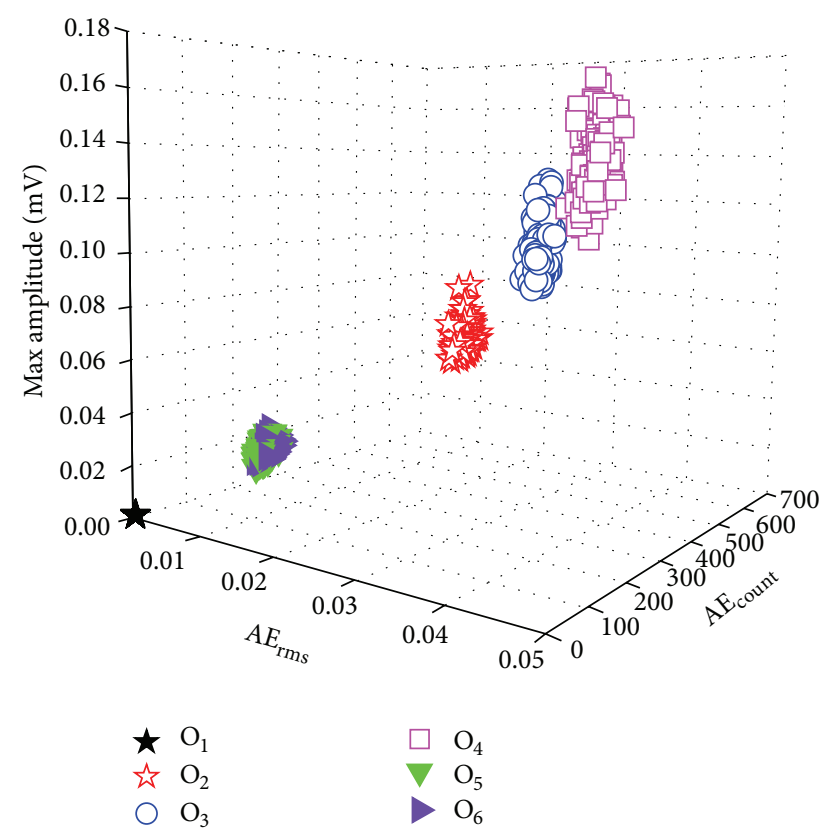

FIGURE 17: Three features of AE signal in 4 bar inlet pressure.

\section{Conflict of Interests}

The authors declare that there is no conflict of interests regarding the publication of this paper.

\section{References}

[1] N. K. Raghuwanshi, A. Pandey, and R. K. Mandloi, "failure analysis of internal combustion engine valves: a review," International Journal of Innovative Research in Science, Engineering and Technology, vol. 1, no. 2, pp. 173-181, 2012.

[2] Z. W. Yu and X. L. Xu, "Failure analysis and metallurgical investigation of diesel engine exhaust valves," Engineering Failure Analysis, vol. 13, no. 4, pp. 673-682, 2006.

[3] J. Mohammadpour, M. Franchek, and K. Grigoriadis, "A survey on diagnostics methods for automotive engines," in Proceedings of the American Control Conference (ACC '11), pp. 985-990, San Francisco, Calif, USA, July 2011.

[4] W. Kaewwaewnoi, A. Prateepasen, and P. Kaewtrakulpong, "Investigation of the relationship between internal fluid leakage through a valve and the acoustic emission generated from the leakage," Measurement, vol. 43, no. 2, pp. 274-282, 2010.

[5] J. Mathew, "Machine condition monitoring using vibration analysis," Journal of the Australia Acoustical Society, vol. 15, no. 1, pp. 7-13, 1987.

[6] J. A. Steel and R. L. Reuben, "Recent developments in monitoring of engines using acoustic emission," The Journal of Strain Analysis for Engineering Design, vol. 40, no. 1, pp. 45-57, 2005.

[7] D. P. Lowe, W. Wu, A. C. C. Tan, and R. J. Brown, "Diesel engine problems, acoustic emission signals and simulated misfire faults," in Proceedings of the 5th World Congress on Engineering Asset Management and Infrastructure Sustainability, pp. 587598, Queensland, Australia, 2012.

[8] A. K. Francis, J. D. Gill, R. L. Reuben, and J. A. Steel, "Investigation into identification of faults in a small HSDI diesel engine using acoustic emission," in Proceedings of the 26th European Conference on Acoustic Emission Testing, pp. 311-320, Berlin, Germany, September 2004.

[9] R. M. Douglas, J. A. Steel, and R. L. Reuben, "A study of the tribological behaviour of piston ring/cylinder liner interaction in diesel engines using acoustic emission," Tribology International, vol. 39, no. 12, pp. 1634-1642, 2006.

[10] A. Albarbar, F. Gu, and A. D. Ball, "Diesel engine fuel injection monitoring using acoustic measurements and independent component analysis," Measurement, vol. 43, no. 10, pp. 13761386, 2010.

[11] T. R. Lin, A. C. C. Tan, and J. Mathew, "Condition monitoring and diagnosis of injector faults in a diesel engine using incylinder pressure and acoustic emission techniques," in Proceedings of the 14th Asia Pacific Vibration Conference (APVC '11), pp. 454-463, Hong Kong, China, 2011.

[12] D. P. Lowe, W. Wu, T. R. Lin, and A. C. C. Tan, "Diesel knock combustion and its detection using acoustic emission," Journal of Acoustic Emission, vol. 29, pp. 78-88, 2011.

[13] W. Abdou, N. Balondimos, and B. Reuben, "Acoustic emission in diesel engines-towards a time series model for the injection process," in Proceedings of the 30th European Conference on Acoustic Emission Testing \& 7th International Conference on Acoustic Emission, pp. 394-406, Granada, Spain, 2012.

[14] M. El-Ghamry, J. A. Steel, R. L. Reuben, and T. L. Fog, "Indirect measurement of cylinder pressure from diesel engines using acoustic emission," Mechanical Systems and Signal Processing, vol. 19, no. 4, pp. 751-765, 2005.

[15] A. Albarbar, F. Gu, A. Ball, and A. Starr, "Internal combustion engine lubricating oil condition monitoring based on vibroacoustic measurements," Insight, vol. 49, no. 12, pp. 715-719, 2007.

[16] T. L. Fog, E. R. Brown, H. S. Hansen et al., "On condition monitoring of exhaust valves in marine diesel engines," in Proceedings of the 9th IEEE Workshop on Neural Networks for Signal Processing (NNSP '99), vol. 9, pp. 554-563, Madison, Wis, USA, August 1999.

[17] F. Elamin, Y. Fan, F. Gu, and A. Ball, "Diesel engine valve clearance detection using acoustic emission," Advances in Mechanical Engineering, vol. 2010, Article ID 495741, 7 pages, 2010.

[18] E. Y. Kim, A. C. C. Tan, and B. S. Yang, "Acoustic emission for diesel engine monitoring: a review and preliminary analysis," in Proceedings of the 5th World Congress on Engineering Asset Management (WCEAM '12), pp. 489-499, Queensland, Australia, 2012.

[19] J. D. Gill, R. L. Reuben, M. Scaife, E. R. Brown, and J. A. Steel, "Detection of diesel engine faults using acoustic emission," in Proceedings of the 2nd International Conference on Planned Maintenance, Reliability and Quality, pp. 57-61, Oxford, UK, 1998.

[20] A. Albarbar, F. Gu, A. Ball, and A. Starr, "On acoustic measurement-based condition monitoring of internal combustion engines," Insight, vol. 50, no. 1, pp. 30-34, 2008.

[21] T. L. Fog, L. K. Hansen, J. Larsen et al., "Exhaust valve leakage detection in large diesel engines," in Proceedings of the 11th International Conference on Condition Monitoring and Diagnostic Engineering Management (COMADEM '98), vol. 1, pp. 269-278, Tasmania, Australia, 1998.

[22] M. Paliwal and U. A. Kumar, "Neural networks and statistical techniques: a review of applications," Expert Systems with Applications, vol. 36, no. 1, pp. 2-17, 2009. 

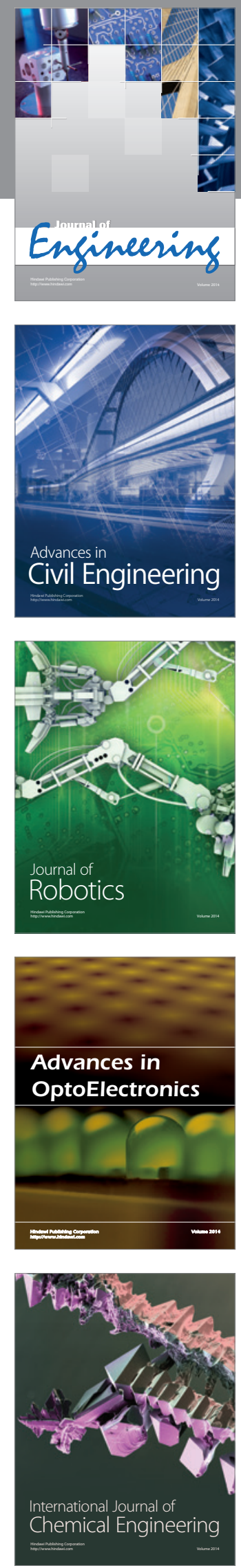

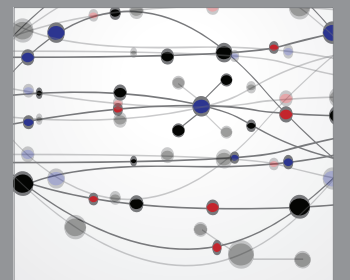

The Scientific World Journal
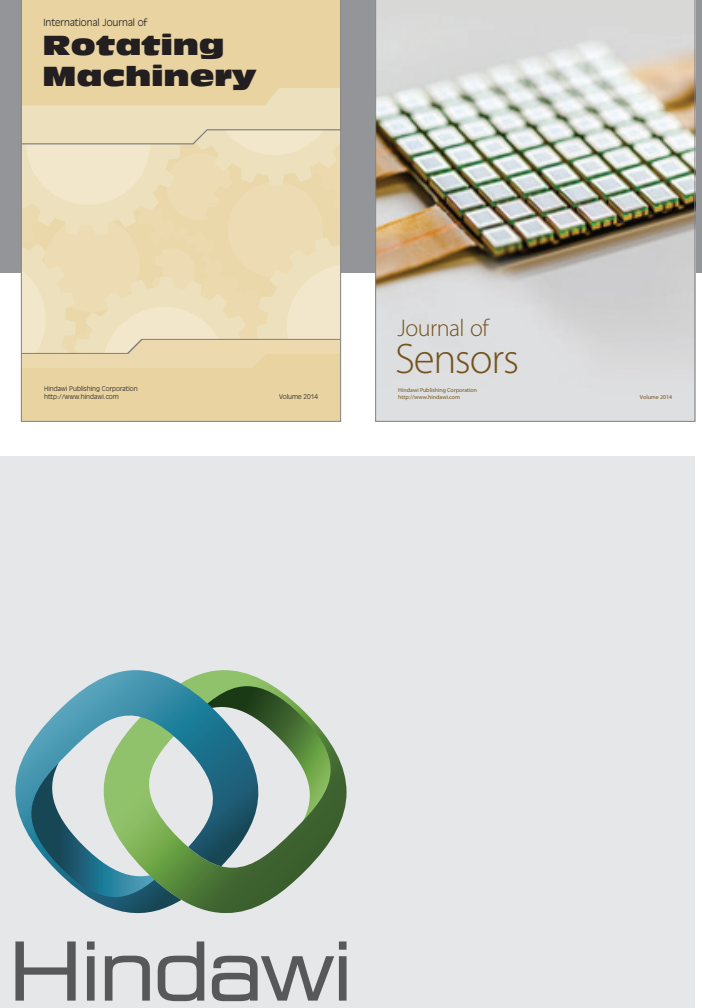

Submit your manuscripts at http://www.hindawi.com
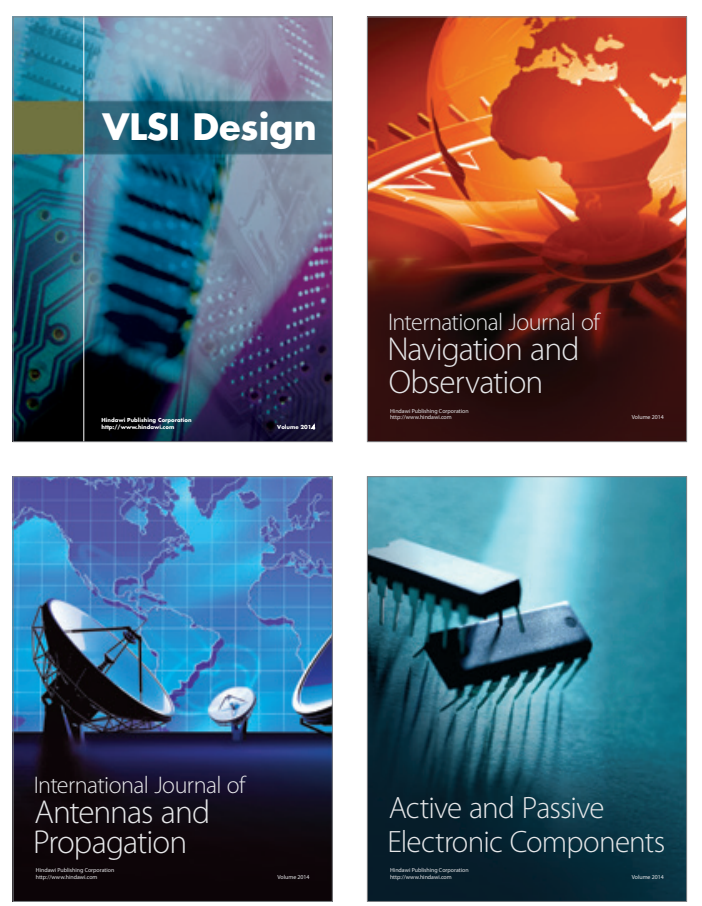
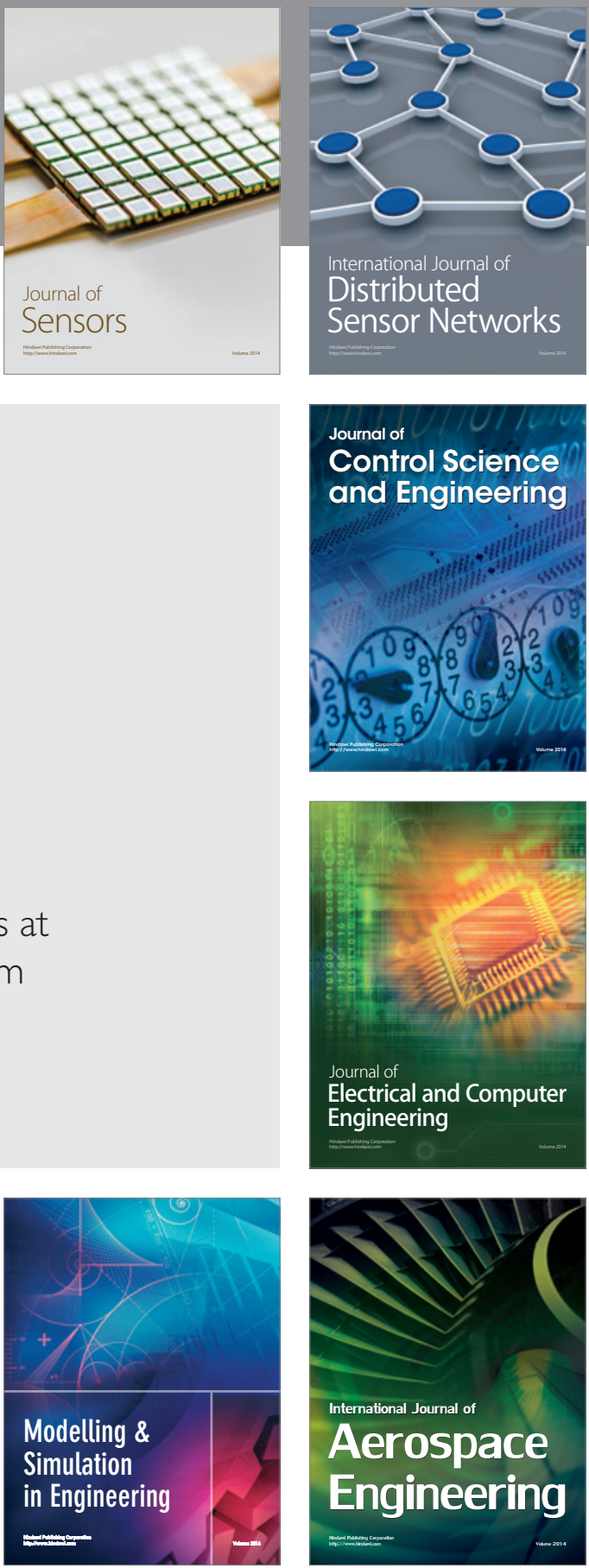

Journal of

Control Science

and Engineering
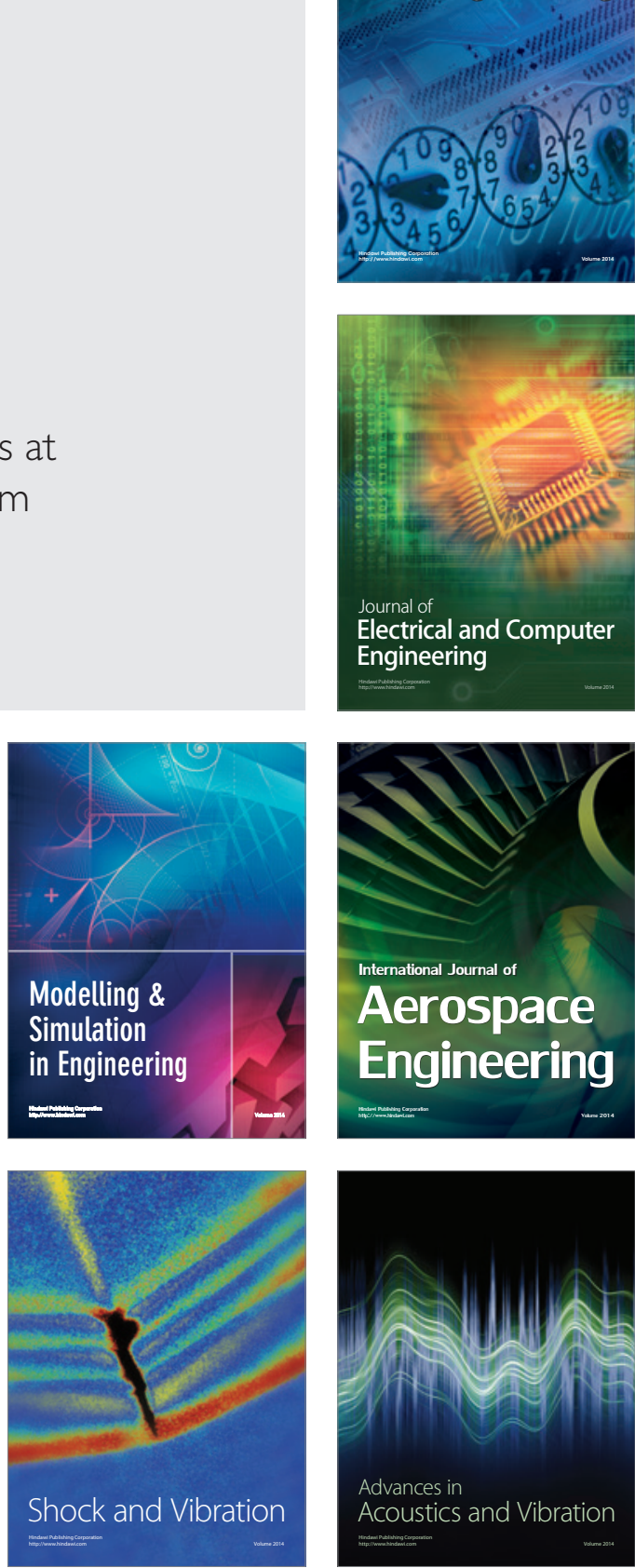